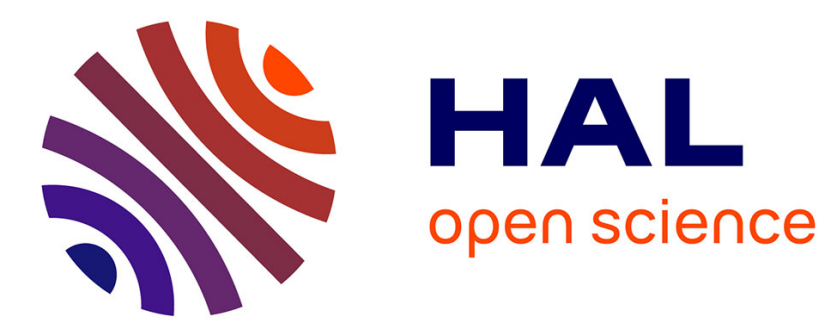

\title{
Te Inclusions in CdTe grown from a slowly cooled Te solution and by the travelling solvent method
}

\author{
R.J. Dinger, I.L. Fowler
}

\section{To cite this version:}

R.J. Dinger, I.L. Fowler. Te Inclusions in CdTe grown from a slowly cooled Te solution and by the travelling solvent method. Revue de Physique Appliquée, 1977, 12 (2), pp.135-139. 10.1051/rphysap:01977001202013500 . jpa-00244132

\section{HAL Id: jpa-00244132 https://hal.science/jpa-00244132}

Submitted on 1 Jan 1977

HAL is a multi-disciplinary open access archive for the deposit and dissemination of scientific research documents, whether they are published or not. The documents may come from teaching and research institutions in France or abroad, or from public or private research centers.
L'archive ouverte pluridisciplinaire HAL, est destinée au dépôt et à la diffusion de documents scientifiques de niveau recherche, publiés ou non, émanant des établissements d'enseignement et de recherche français ou étrangers, des laboratoires publics ou privés. 


\title{
Te INCLUSIONS IN CdTe GROWN FROM A SLOWLY COOLED Te SOLUTION AND BY THE TRAVELLING SOLVENT METHOD
}

\author{
R. J. DINGER $(*)$ and I. L. FOWLER $(* *)\left({ }^{+}\right)$ \\ Chalk River Nuclear Laboratories Atomic Energy of Canada Limited \\ Chalk River, Ontario, Canada KOJ 1JO
}

\begin{abstract}
Résumé. - On décrit la croissance de cristaux de tellurure de cadmium en solvant tellure et par la méthode "THM ». La densité des inclusions de tellure dans les cristaux a été étudiée ; on a pu montrer que dans une certaine gamme de vitesses de croissance et de gradients de température, il est possible d'obtenir des cristaux dépourvus d'inclusions de tellure.
\end{abstract}

\begin{abstract}
CdTe crystals have been grown from a slowly cooled Te solution and with the travelling solvent method. The density of visible Te inclusions in the crystals has been investigated and it was found that inclusion-free material can be grown if the growing speed and the temperature gradient in the melt are kept within certain limits.
\end{abstract}

1. Introduction. - CdTe crystals for nuclear radiation detectors are usually grown from a slowly cooled solution or with the travelling solvent method. Both techniques use $\mathrm{Te}$ as the solvent and the basic phenomena at the solid-liquid interface are therefore very similar. The differences between the two techniques may be seen when the parameters controlling the crystal growth are compared.

Table I gives the values for the temperature, $T_{0}$, at the solid-liquid interface, the temperature gradient, $\partial T / \partial x$, in the melt and the crystal growing speed, $v$, obtained with the equipment used in our laboratory to grow CdTe crystals.

\section{TABLE I}

The crystal-growth parameters, temperature, $T_{0}$, temperature gradient, $\partial T / \partial x$, and growing speed, $v$, for the slowly cooled solution and travelling solvent growth.

$\begin{array}{lcccc} & T_{0} & \partial T / \partial x & v \\ \begin{array}{l}\text { Slowly cooled } \\ \text { solution }\end{array} & 650-900^{\circ} \mathrm{C} & 0.1-5 \overline{{ }^{\circ} \mathrm{C}} \cdot \mathrm{mm}^{-1} & 0.5-100 \overline{\mathrm{mm}} \cdot \mathrm{h}^{-1} \\ \begin{array}{c}\text { Travelling sol- } \\ \text { vent }\end{array} & 800-900^{\circ} \mathrm{C} & 5-10^{\circ} \mathrm{C} \cdot \mathrm{mm}^{-1} & 1 & \mathrm{~mm} \cdot \mathrm{h}^{-1}\end{array}$

The table shows that the crystal-growth parameters change much more during the growth of a crystal with

(*) National Research Council of Canada Postdoctorate Fellow now at Ebauches S. A., Direction technique, 1 Faubourg de l'Hôpital, CH-2001 Neuchâtel, Switzerland.

$(* *)$ Deceased.

(+) Paper read by J. G. V. Taylor. the slowly cooled solution method than with the travelling solvent method : in the former case the temperature varies by $200^{\circ} \mathrm{C}$ and the growing speed by two orders of magnitude. The change in temperature gradient during the growth of a given crystal is, with both methods, about a factor of 1.5 to 2 . A range of two orders of magnitude has been covered for the growing speed $v$ and the temperature gradient $\partial T / \partial x$.

This paper deals with the influence of these growth parameters on the inclusions of $\mathrm{Te}$ which are often seen in CdTe crystals. Te inclusions are observed to occur in two different habitats. The first is at places where the growth of the crystal has been obstructed by neighbouring crystals or the ampoule wall in such a way that some Te must solidify inside the CdTe because its connection with the main body of the solvent has been cut off. These inclusions are often numerous and large enough to be visible as metallic shiny spots on a polished crystal sample. Since material showing numerous or large inclusions is useless for detector applications, inclusions of this type are not dealt with here. Inclusions of a second type occur at the crystal growing surface as a consequence of its instability ; they are visible within single crystals and often form regular arrays of small Te droplets as observed by infrared transmission microscopy. In this paper the influence of the growing parameters on Te inclusions of this second type is discussed.

2. Theory. - When a crystal is grown from a solution, the solvent is rejected from the solid-liquid interface and the resultant solvent concentration, $n_{\mathrm{s}}$, is greatest at the interface, $x=0$ in figure $1 a$. Within an interface layer of thickness $\delta$ the gradient of the solvent 


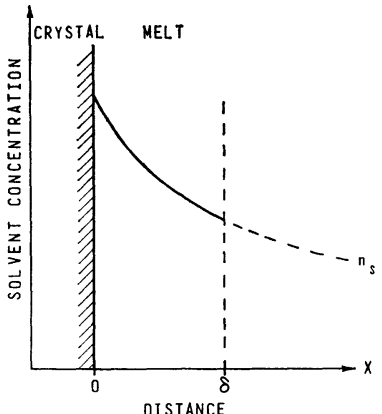

a)

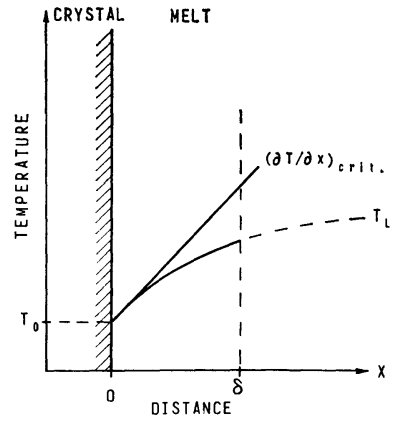

b)
FIG. 1. - Solvent concentration, $\boldsymbol{n}_{\mathrm{s}}$, and liquidus temperature $T_{\mathrm{L}}$, in the diffusion-controlled layer, $\delta$, ahead of the solid-liquid interface during crystal growth.

concentration is controlled by diffusion. The liquidus temperature $T_{\mathrm{L}}$ (the temperature of a saturated solution of concentration $n_{\mathrm{s}}$ as given by the phase diagram [1]) corresponding to the solvent concentration in figure $1 a$ is shown in figure $1 b$. It takes on its lowest value, $T_{0}$, where the solvent concentration is highest, i. e. at the solid-liquid interface and $T_{0}$ must be the actual temperature at the interface for stable crystal growth. If the temperature anywhere in the melt drops below the $T_{\mathrm{L}}$ curve constitutional supersaturation (CSS) occurs. From the figure it may be seen that in the diffusion-controlled layer ahead of the interface the actual temperature gradient must equal or exceed a critical value $(\partial T / \partial x)_{\text {crit }}$, if unstable growing conditions associated with CSS are to be avoided. Since the solvent gradient $\partial n_{\mathrm{s}} / \partial x$ becomes steeper with increasing crystal growing speed, $v$, the critical temperature gradient increases with increasing growing speed.

A more quantitative discussion [2-4] of this CSS criterion for stable crystal growth leads to the expression

$$
\frac{v}{\partial T / \partial x}<\frac{D \cdot n_{\mathrm{e}} \cdot \Delta H}{\rho \cdot R \cdot T_{0}^{2}},
$$

where $D$ is the diffusion constant and $n_{\mathrm{e}}$ the equilibrium concentration of $\mathrm{CdTe}$ in the $\mathrm{Te}$ solution, $\Delta H$ the latent heat of crystallization, $\rho$ the density of the CdTe crystal $R$ the gas constant and $T_{0}$ the absolute temperature at the solid-liquid interface.

If the values corresponding to our growth conditions as given in table I are inserted, a critical growing speed of $10^{-3} \mathrm{~mm} \cdot \mathrm{h}^{-1}$ to $10^{-1} \mathrm{~mm} \cdot \mathrm{h}^{-1}$ is obtained from eq. (1). This theoretical prediction is in clear conflict with the experimental results since inclusion-free crystals have been grown with growing speeds of about $1 \mathrm{~mm} \cdot \mathrm{h}^{-1}$. It should be mentioned however that eq. (1) was derived assuming a perfectly flat crystal-growing front (i. e. the solid-liquid interface to be an infinite plane). If the crystal growing front takes a threedimensional shape (e. g. like a honeycomb) the total surface area increases thus reducing the solvent gradient and increasing the maximum permissible crystal growing speed, $v$. In addition, convective mixing (due to the temperature gradients inside the ampoule) stabilize the growing surface [3]. Since these phenomena are not easily accessible to a theoretical study an experimental investigation seems to be a more appropriate way to obtain quantitative figures for the limits for the crystal growing parameters set by the occurrence of Te inclusions.

3. Crystal growth. - For the growth of CdTe crystals from a slowly cooled solution the arrangement used in our laboratory is substantially the same as described by Zanio et al. [5]. An evacuated ampoule containing a total charge of $200 \mathrm{~g}$ of CdTe and Te in a ratio corresponding to a saturated solution at $900{ }^{\circ} \mathrm{C}$ is either suspended above or rests on a suitable cooling arrangement inside a vertical tubular furnace of $6 \mathrm{~cm}$ bore. The furnace is heated to about $1000^{\circ} \mathrm{C}$ and the ampoule is stirred at that temperature (by rotating at 0.5 revolutions per second and changing the direction of the rotation every 30 seconds) for $10-15 \mathrm{~h}$ to ensure proper mixing of the contents. After the stirring has been stopped the furnace is slowly cooled at a rate of $3^{\circ} \mathrm{C} \cdot \mathrm{h}^{-1}$

Three different arrangements, illustrated in figure 2 , were used to cool the lower end of the ampoules.
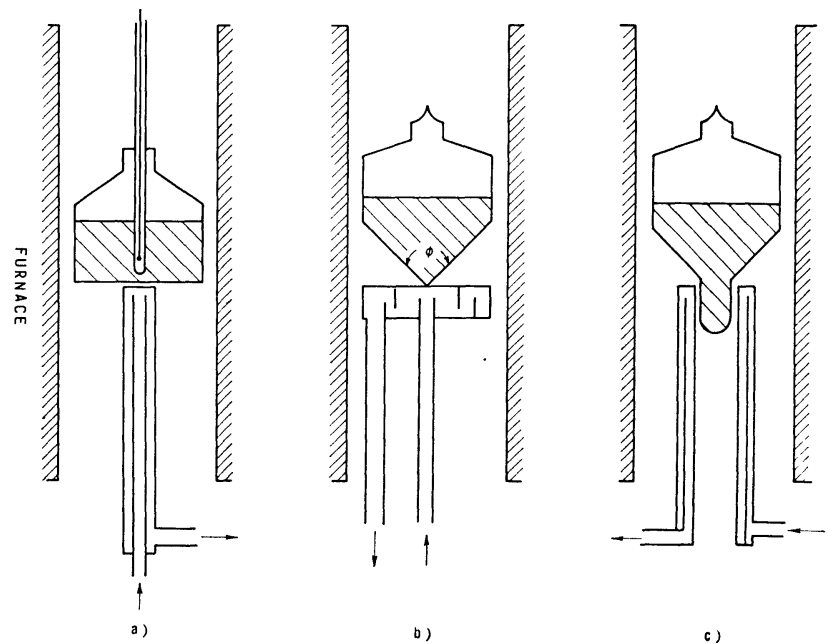

Fig. 2. - Schematic representation of different arrangements for the growth of CdTe crystals from a slowly cooled solution. For explanation see text.

Cooling is necessary in order to initiate crystal growth at a defined location in the ampoule and to provide the required temperature gradient inside the ampoule. The first crystals were grown using a cooling finger as described by Zanio et al. [5] and sketched in figure $2 a$. Two coaxial stainless steel tubes, the outside one closed at the upper end, are cooled by air passing through them in the direction of the arrows. The ampoule rests on top of the outside tube and is cooled principally by thermal conductivity. Depending on the air flow a temperature gradient in the melt of up to $1^{\circ} \mathrm{C} \cdot \mathrm{mm}^{-1}$ 
could be achieved. The temperature gradient was measured by inserting a thermocouple into a thin quartz tube sealed vertically into the ampoule, as shown in the figure. Since the thermal conductivity between the ampoule bottom and the top of the cooling finger could not be reproduced reliably, this arrangement was replaced by the one shown in figure $2 b$. A conical ampoule rests on the air-cooled plate. The ampoule is cooled almost entirely by radiation and for geometrical reasons most of the cooling occurs at the tip of the ampoule thus leading to a well defined starting point for the crystallization. A temperature gradient of up to $1.5^{\circ} \mathrm{C} . \mathrm{mm}^{-1}$ could be achieved with this arrangement. Very much larger gradients - up to $10^{\circ} \mathrm{C} . \mathrm{mm}^{-1}$ can be obtained with the water-cooled arrangement shown in figure $2 c$ [6]. A conical ampoule with a nippleshaped projection extending into the cooling tube is used with this system. All temperature gradients were measured at a melt temperature of $900^{\circ} \mathrm{C}$.

With the slow-cooling method of crystal growth, the growing speed, $v$, is given by the cooling rate and to a lesser extent by the ampoule shape and may be calculated from the CdTe phase diagram [1]. For our experimental conditions, the result is plotted in figure 3 for ampoules with a cone angle $\phi$ of $90^{\circ}$. experimental conditions, the result is plotted in figur For flat-bottomed ampoules, assuming hemispherical

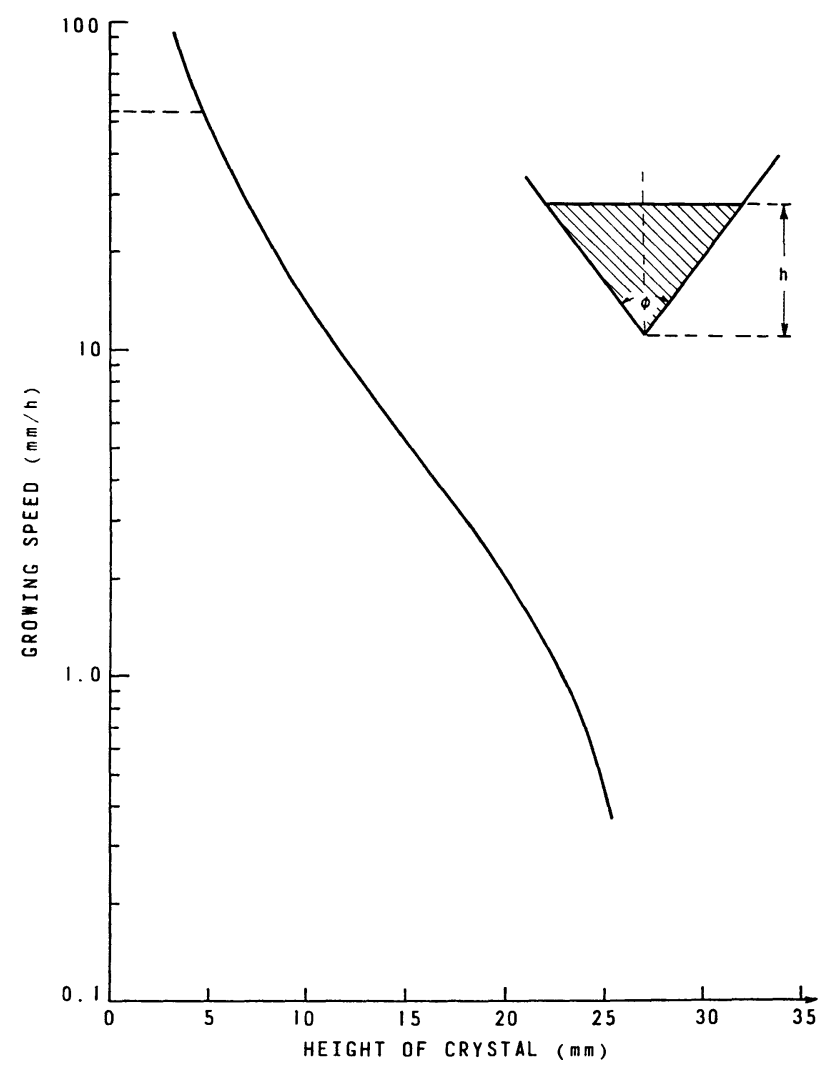

FIG. 3. - Growing speed, $v$, as a function of the height, h, of the solid-liquid interface for the growth from a slowly cooled solution with a conical ampoule of $\varphi=90^{\circ}$. For the ampoules shown in figure $2 c$ the dashed line holds. For ampoules with a flat bottom the growing speed is a quarter of the plotted values. crystal growth, the growing speed is a quarter of the values plotted in figure 3. As shown in the insert, the abscissa shows the height (or radius) of the already grown crystal. The figure shows that the growing speed varies during the crystal growth by about two orders of magnitude.

The apparatus used for the growth of CdTe crystals by the travelling solvent method is similar to the arrangement described by Tranchart and Bach [7]. With this technique a constant growing speed of $1 \mathrm{~mm} \cdot \mathrm{h}^{-1}$ was maintained and the temperature gradient in the melt was $10^{\circ} \mathrm{C} \cdot \mathrm{mm}^{-1}$. The diameter of the crystals was $10 \mathrm{~mm}$.

4. Te inclusions. - To observe the Te inclusions, slices $2 \mathrm{~mm}$ thick were cut from the crystals, polished on both sides and examined by transmission infrared microscopy. The eyepiece of an otherwise unmodified microscope (Reichert Mod. MeF2) was replaced by an infrared image converter (FJW Mod. 80378) and the picture could either be observed directly after the image converter or a single lens reflex camera (Nikkormat Mod. FT2) could be attached for taking photographs.

Six examples are given in figure 4. The photographs were taken along a single vertical slice from a crystal grown from a slowly cooled solution at increasing distances (height, see caption) from the tip of the crystal. The photograph taken at a height of $5 \mathrm{~mm}$ shows that there are many inclusions while in the later stages of crystal growth the density of inclusions becomes considerably smaller. Note, in photographs $e$ and $f$, the regular arrangement of the inclusions, which is approximately parallel to the direction of the crystal growth.

The photographs show a gradual change from crystals showing a high density of inclusions to almost inclusion-free material, while the theory would predict a sharp transition if the simplifying assumptions made in deriving eq. 1 were valid. The samples have been classified, by direct comparison of the infrared photographs, according to the density of Te inclusions. In this classification, zero corresponds to inclusion-free material and ten to crystals having such a high density of inclusions that the photographs are totally black. For the examples shown in figure 4 , the classification was 8 for picture $a, 4$ for $b, 3$ for $c$, and 2 for $d, e$ and $f$. This classification scheme was used to investigate the correlation of the density of inclusions with the parameters $T_{0}, \partial T / \partial x$ and $v$.

No significant correlation between the density of Te inclusions and the temperature $T_{0}$ could be observed. This lack of correlation partly arises from the fact that the temperature dependence of the diffusion constant and the $T_{0}^{2}$-term in eq. (1) cancel each other to some extent such that the net effect of the temperature cannot be seen with this method and partly from the relatively high scatter in the results (cf. Fig. 5 and 6). 


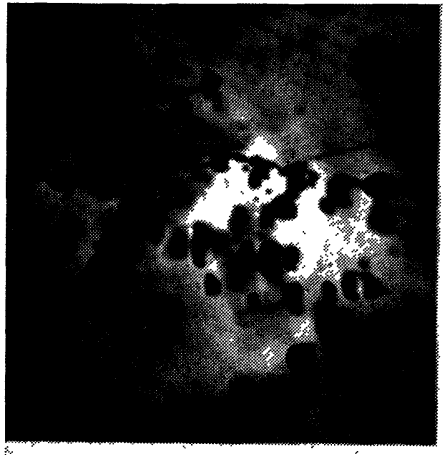

a

DIRECTION

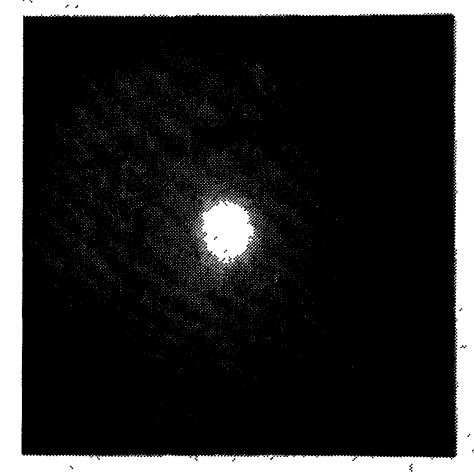

d

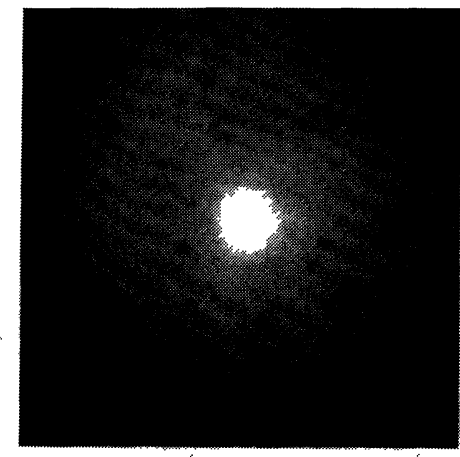

b

OF CRYSTAL GROWTH

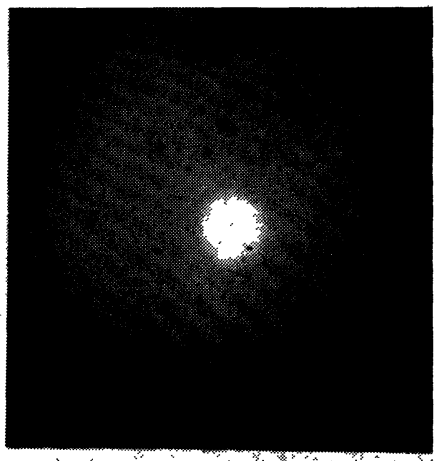

c

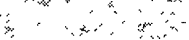
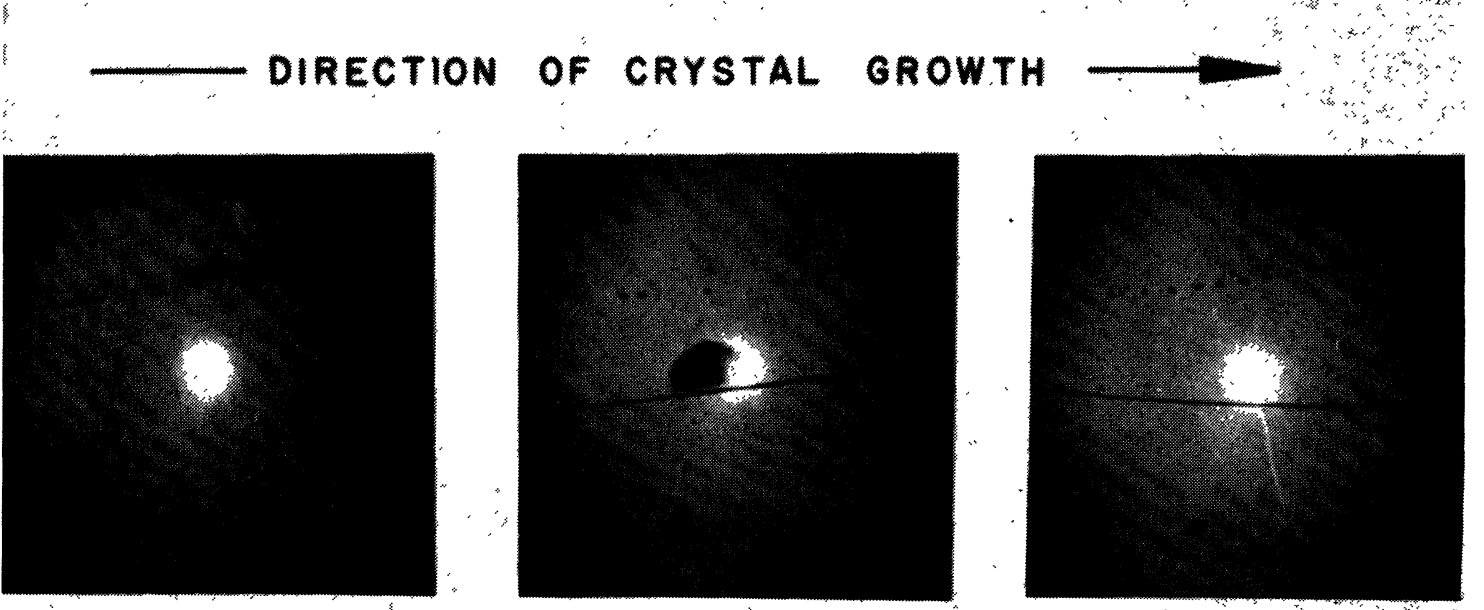

e
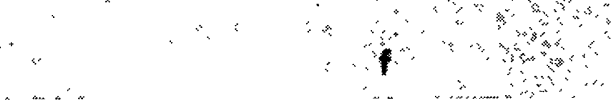

FIG. 4. - Infrared micro-photographs taken along a single vertical slice of a crystal showing Te inclusions (black). The total magnification is about 100. Picture (a) was taken at a height of $5 \mathrm{~mm}$ from the tip of a crystal grown with the slowly cooled solution method, picture $(b)$ was taken at $10 \mathrm{~mm}$, picture $(c)$ at $15 \mathrm{~mm},(d)$ at $17.5 \mathrm{~mm},(e)$ at $20 \mathrm{~mm},(f)$ at $22.5 \mathrm{~mm}$ from the same crystal.

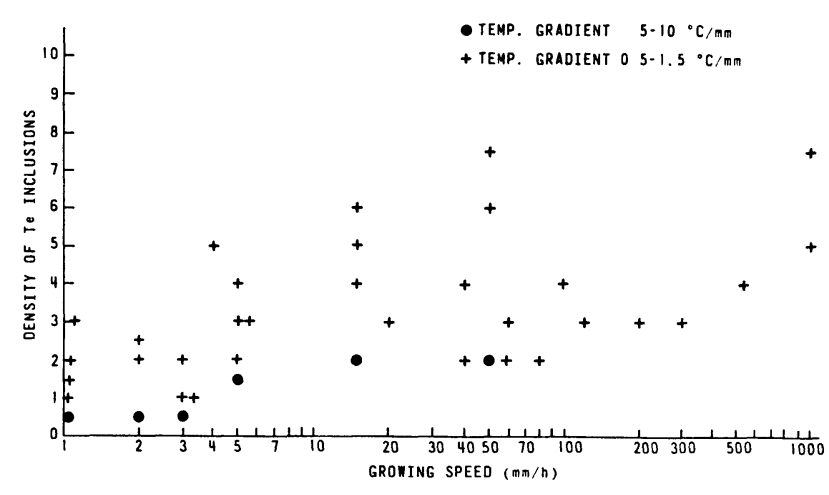

FIG. 5. - Density of Te inclusions as a function of the crystal growing speed, $v$. The density of inclusions is given in arbitrary units explained in the text.

There are however correlations between the density of Te inclusions and both the growing speed $v$ (Fig. 5) and the temperature gradient $\partial T / \partial x$ in the melt (Fig. 6). As expected the material shows fewer inclusions for slower crystal growth and higher temperature gradients. It may also be seen that there is a transition, extending over a range of several orders of magnitude

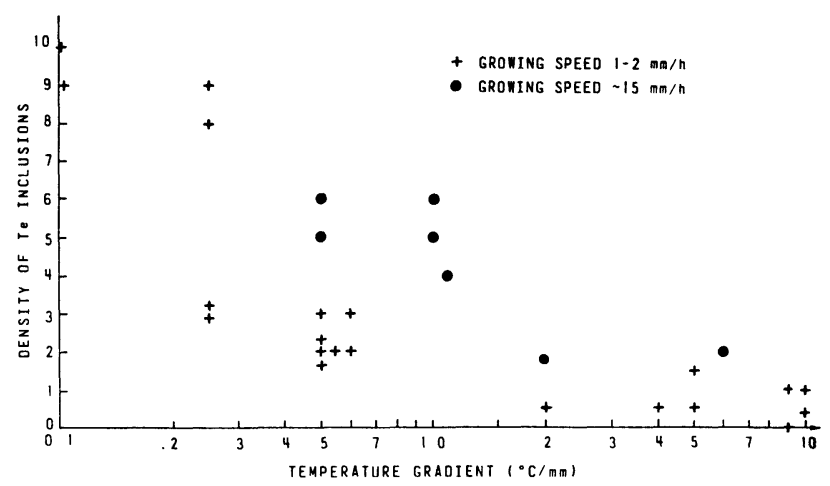

FIG. 6. - Density of Te inclusions as a function of the temperature gradient in the melt $\partial T / \partial x$. The density of inclusions is given in arbitrary units as explained in the test.

of the parameters $v$ and $\partial T / \partial x$ from the inclusion-free material to crystals showing a very high density of inclusions. In addition there is considerable scatter in the experimental results which shows that the parameters $v$ and $\partial T / \partial x$ do not completely control the conditions at the growing interface and, hence, that microscopic effects have a strong influence. Figures 5 
and 6 show, however, that Te inclusions can be avoided if a growing speed of $1 \mathrm{~mm} \cdot \mathrm{h}^{-1}$ is not exceeded significantly and if a temperature gradient in the melt of $5-10^{\circ} \mathrm{C} \cdot \mathrm{mm}^{-1}$ is maintained.

5. Discussion. - As suggested by a simple thcoretical analysis which assumes the morphological stability of the growing interface to be the criterion for the occurrence of solvent inclusions, the existence of $\mathrm{Te}$ inclusions depends on two crystal growing parameters : the crystal growing speed $v$ and the temperature gradient $\partial T / \partial x$. The model does not, however, allow any quantitative predictions to be made since it is found experimentally that crystal growing speeds one hundred times larger than the limit given by the model still lead to inclusion-free crystals. In addition, the simple model predicts a sharp transition from inclusionfree crystals to material containing $\mathrm{Te}$ incluisons at some critical values for the parameters $v$ and $\partial T / \partial x$, whereas the experiment shows a smooth transition between these two extreme situations over two decades of range of the parameters.

CdTe crystals were grown from a slowly cooled $\mathrm{Te}$ solution and by the travelling solvent method and the experiments show that inclusion-free material can be grown with both of these techniques provided the crystal growing speed is below $2-3 \mathrm{~mm} \cdot \mathrm{h}^{-1}$ and the temperature gradient above $5^{\circ} \mathrm{C} . \mathrm{mmm}^{-1}$.

Acknowledgements. - The authors are grateful to Dr. H. Schmeing for his contribution to the slowly coded solution technique, especially the water cooling arrangement in figure $2 c$. We are indebted to M. M. L. Racicot, W. F. Slater, R. J. Toone and W. J. Woytowich for assistance in various phases of the work and to J. G. V. Taylor for reading the paper. A Postdoctorate Fellowship from the National Research Council is also gratefully acknowledged.

\section{References}

[1] De Nobel, D., Philips Res. Rept. 14 (1959) 361.

[2] Tiller, W. A., J. Cryst. Growth 2 (1968) 69.

[3] Scheel, H. J. and Elwell, D., J. Electrochem. Soc. 120 (1973) 818.

[4] Rosenberger, F., Delong, M. C., Greenwell, D. W.,
Olson, J. M. and Westphal, G. H., J. Cryst. Growth 29 (1975) 49.

[5] Zanio, K., Montano, H. and Krajenbrink, F., IEEE Trans. NS-21 (1974) 315 .

[6] Schmeing, H., unpublished work (1976).

[7] TrancharT, J. C. and BaCH, P., J. Cryst. Growth 32 (1976) 8. 